\title{
O Estado Novo e sua relação com os imigrantes: a língua como defesa dos valores nacionais
}

Alexandre Marcelo BUENO

(Universidade de São Paulo)

RESUMO: Ao propor uma idéia de homogeneidade cultural brasileira, o texto de Oliveira Viana, analisado neste trabalho, constrói uma imagem negativa de certos grupos imigrantes por considerá-los “inassimiláveis”. Dessa forma, abre-se espaço para a construção de um discurso intolerante e, mais especificamente, para a intolerância lingüística.

PALAVRAS-CHAVE: intolerância lingüística; imigração; História do Brasil; semiótica discursiva

RÉSUMÉ: Lorsqu'il cherche à imposer l' idée d'homogénéité culturelle brésilienne, le texte d'Oliveira Viana analysé dans ce travail construit une image négative de certains groupes d'immigrés considérés "non assimilables". Dès lors la voie est ouvert à la construction d'un discours intolérant et, plus spécifiquement, à l'intolérance linguistique.

MOTS-CLÉS: intolérance linguistique; immigration; histoire du Brésil; sémiotique discursive 


\section{INTRODUÇão}

Oliveira Viana publicou no jornal A Manhã, em 5 de novembro de 1943, um texto intitulado "Imigração e colonização ontem e hoje". Nele, o autor comparou as duas legislações que regulavam a imigração e a colonização na Primeira República e na Era Vargas. Realizou, assim, uma espécie de "balanço" da imigração no Brasil, mostrando os aspectos negativos da legislação "liberal" a respeito da imigração na Primeira República e, conseqüentemente, os elementos positivos das leis imigratórias da Era Vargas.

O texto analisado defende que a legislação do regime político anterior criou, por conta de seu liberalismo, as condições para a formação de colônias homogêneas e isoladas do restante da sociedade brasileira, colônias encaradas, assim, como um problema nacional a ser resolvido. É justamente esse caráter "problemático" da imigração que possibilita a construção de um discurso intolerante e preconceituoso.

\section{DISCURSOS INTOLERANTES E A INTOLERÂNCIA LINGÜÍSTICA}

Para analisarmos a relação entre a sociedade e o Estado brasileiros e os imigrantes, utilizamos o modelo de relação entre identidade e alteridade, elaborado por Landowski (2002) no qual o autor utiliza os seguintes conceitos (baseados na oposição entre a conjunção e a disjunção e seus contrários): assimilação, exclusão, adesão e segregação.

De modo resumido, na assimilação ocorre a conjunção total da alteridade na identidade, ou seja, o outro perde seu estatuto de alteridade porque de certa forma renega (ou se vê obrigado a renegar) os seus valores e suas características constituintes. Na exclusão, há uma disjunção total entre identidade e alteridade, na qual as diferenças permanecem à distância, sem se misturar (Landowski, 2002:8-9). Ambas, assimilação e exclusão, assentam-se, do nosso ponto de vista, em uma concepção de identidade e alteridade absolutas.

Já no conceito de admissão, as diferenças existentes entre identidade e alteridade convivem pacificamente sem se tornar uma tensão ou um problema (ou seja, prevalece a co-existência e o reconhecimento mútuo). Enquanto na segregação, haveria um limite bem estabelecido entre a identidade e a alteridade sem, contudo, se tentar afastar totalmente a alteridade e os seus valores, uma vez que os valores da identidade não estariam ameaçados (Landowski, 2002:16-21). Assim, entre esses dois conceitos, não ocorre nem uma conjunção nem uma disjunção totais entre identidade e alteridade.

Se observarmos o fenômeno da intolerância, veremos que ela está presente em diversas ações que visam a fazer mal a um outro (terrorismo, xenofobia, anti-semitismo, racismo, etc.). Para Paul Ricoeur, há dois componentes necessários para a existência da intolerância: o primeiro é a reprovação das crenças e convicções do outro e o segundo é a capacidade de impedir o outro de exercer e viver suas convicções e crenças (Ricoeur, 2000:20). Sem essa conjugação de elementos, é impossível que a intolerância exista.

Já Françoise Héritier (2000) procura as causas da intolerância (entendida pela autora como a exclusão e a eliminação de grupos sociais) na rejeição do outro a partir de uma idéia de pureza e unicidade (de qualquer natureza) constituinte da identidade. Como afirma a própria autora: 
Um arraigado mecanismo de intolerância e do racismo, inerente à questão da pureza do sangue, consiste na convicção de que os outros não pensam, não sentem, não reagem como nós (qualquer que seja esse 'nós'), que nos consideramos a essência da humanidade e da civilização (Héritier, 2000:24).

Isso significa dizer que a intolerância não pode ser analisada e compreendida em si mesma, mas sempre na relação estabelecida entre ao menos dois sujeitos (isto é, entre uma identidade e uma alteridade). Semioticamente, podemos pensar na intolerância como um fazer e, mais especificamente, como um fazer malevolente (ou seja, fazer o mal a um outro) (Barros, 1988:66), que pressupõe o preconceito, entendido como a crença do sujeito (figurativizado como o Estado, a sociedade, um grupo de indivíduos etc.) de que seus valores são bons e eufóricos e, conseqüentemente, os valores do outro, ruins e disfóricos. Essa crença orienta a interpretação do sujeito em relação ao outro, em que se constrói a imagem negativa da alteridade. Em outras palavras, o sujeito interpretador (ou ainda, o destinador-julgador) é dotado de uma série de valores que ele reconhece e crê como verdadeiros e que servem de parâmetro para a sua interpretação, o seu julgamento e a sua conseqüente ação. E essa ação, que é a própria intolerância, se daria de duas maneiras: pela assimilação ou pela exclusão.

Ao não cumprir determinada ação anteriormente estabelecida por meio do contrato fiduciário, o sujeito é julgado negativamente pelo destinador-julgador (a etapa do preconceito), que aplicará, a depender do sujeito, uma das duas formas de intolerância citada no parágrafo anterior (assimilação ou exclusão), por meio de um novo sujeito que realizará o fazer malevolente (ou seja, a ação característica da intolerância). Cria-se, dessa maneira, uma imagem negativa da alteridade baseada em alguns elementos que a constituem (para justificar sua assimilação ou sua total exclusão do processo de relação em um determinado universo social): seu comportamento, suas crenças, seus valores, sua cultura e também sua língua. Por essa razão, podemos postular a existência de um tipo específico de intolerância: a lingüística.

Em relação aos imigrantes, a intolerância e o preconceito lingüísticos ocorrem de duas formas: uma externa, em relação a determinados idiomas estrangeiros, e uma outra interna, envolvendo as variantes desprestigiadas da língua portuguesa e as suas relações com a norma culta (dentre essas variantes desprestigiadas, haveria aquelas utilizadas pelos imigrantes).

Por isso, devemos pensar na possibilidade de a intolerância lingüística ser um fazer discriminatório independente de outras formas de intolerância, pois os indivíduos estão a todo momento avaliando e julgando uma determinada língua estrangeira e o modo de falar de seus interlocutores, ato que envolve também a construção da imagem da alteridade.

Assim, especificamente na intolerância lingüística, ela ocorre a partir da distinção e posterior discriminação dos elementos ou traços que não se "adequam” aos elementos da língua nacional que, pelo seu caráter "unificador”, se entrelaça com a questão da nacionalidade. Em relação às normas lingüísticas, a identificação desta inadequação lingüística serve para delimitar e segregar certos grupos sociais, que, por conseguinte, podem ser obrigados a se assimilarem, atendendo aos valores impostos de uma língua nacional ou de uma determinada variante da língua. 
A intolerância lingüística se forma, assim, a nosso ver, pela contraposição entre o uso lingüístico e uma certa imagem de língua nacional que permeia o senso comum da sociedade, ou seja, há uma tensão entre a multiplicidade intrínseca à fala e a idealização subjacente ao conceito de língua e de norma, que cria o efeito de sentido de homogeneidade e unicidade (do que é correto ou certo, aquilo que produz e transmite os valores nacionais etc.).

Veremos no texto de Oliveira Viana um tipo específico de intolerância lingüística: a que se refere às línguas estrangeiras e que serve para construir a imagem negativa dos imigrantes.

\section{O BALANÇO DO PROCESSO IMIGRATÓRIO E A CONSTRUÇÃO DOS VALORES NACIONAIS}

Como já dissemos, o texto de Oliveira Viana realiza uma crítica à legislação imigratória "liberal” do governo da Primeira República, em oposição a uma lei mais rigorosa em relação aos imigrantes, vigente na Era Vargas, que não permitiria a manutenção de colônias homogêneas de imigrantes no país. Assim, o texto estabelece uma primeira oposição, entre um regime liberal, mais tolerante, e um outro mais rigoroso e controlador da presença de imigrantes no país.

Observamos essa oposição já no primeiro parágrafo do texto:

Quem lê a nossa velha legislação sobre imigração e colonização é que pode sentir a profunda diferença, senão o antagonismo, dos dois regimes - o das nossas antigas leis imigratórias, fundadas no soi-disant liberalismo da Constituição de 1941 [sic] ${ }^{1}$, e o das duas novas Constituições revolucionárias - a de 1934 e a de 1937 - com as suas prescrições limitativas, controladoras e orientadoras das correntes imigratórias (Viana, 1991:383).

Segundo o texto, a legislação da Primeira República acerca da imigração estava apenas preocupada com a questão econômica, do "imigrante-trabalho" e na ocupação do solo (Viana, 1991:383), ou seja, procurava apenas o sujeito competente para um determinado fazer. Por isso, descuidou das questões cultural e lingüística que se relacionavam ao tema da nacionalidade: a legislação brasileira do governo anterior foi considerada "sem nenhuma atenção à sua qualidade [do imigrante] como elemento plasmador da nacionalidade [brasileira]” (idem). Em outras palavras, o governo da Primeira República não teria atentado para o fato de que imigrantes, para o bem e para o mal, contribuiriam para a formação da nacionalidade brasileira, por estar apenas preocupado com a questão econômica, do fazer do imigrante. Por isso, a legislação anterior não se preocupava com o fato de certos grupos imigrantes serem portadores de uma cultura tão diferente da brasileira a ponto de se reunirem em núcleos coloniais homogêneos para preservar sua tradição, sua religião, seus costumes e sua língua. Por isso, na Primeira República, havia apenas a preocupação de impedir a entrada de “elementos cacogênicos ou disgênicos” (ibidem), ou seja, para o governo anterior, só interessava a entrada de imigrantes sadios e aptos para o trabalho no campo. Dessa maneira, impedia-se a entrada de sujeitos incompetentes, ou seja, que não tinham a modalidade do poder-fazer para que se tornassem adjuvantes no programa narrativo do 
desenvolvimento econômico do país. Não havia, por essa razão, qualquer tipo de preocupação quanto a questões culturais, que remetiam diretamente para a nacionalidade dos imigrantes e para a questão do ser.

Um dos exemplos apresentados pelo texto para mostrar a tolerância do governo da Primeira República foi o do prêmio, na forma de viagens aos países de origem, para os imigrantes que mais produzissem em suas respectivas colônias. Dessa forma, ao invés de incentivar a integração do imigrante, esse tipo de prêmio, segundo o texto, apenas reforçaria os "sentimentos nativos" deles porque retornariam ao Brasil revigorados em relação à sua origem.

Com isso, para contar com o auxílio desses imigrantes-adjuvantes, o governo da Era Vargas deveria reelaborar os valores em jogo na manipulação dos sujeitos. Restaria ao governo Vargas fazer alterações na legislação imigratória para promover a integração dos imigrantes na sociedade brasileira. Essa integração seria a única maneira de os imigrantes deixarem de ser considerados uma ameaça à homogeneidade nacional, ou seja, como anti-sujeitos ou anti-adjuvantes. Era, portanto, inadmissível a manutenção dos traços estrangeiros e estranhos nos núcleos coloniais porque poderia haver uma “deturpação” no caráter nacional do Brasil, isto é, do objeto de valor a ser construído. Além disso, o Estado brasileiro, que acolheu os imigrantes, deveria ser soberano em relação a eles, ou seja, não era o país que deveria aceitar elementos e valores estrangeiros em seu próprio solo, mas sim os imigrantes é que deveriam aceitar e acatar os valores brasileiros. É por isso que podemos dizer que esse é um discurso intolerante e preconceituoso: ao reelaborar o contrato fiduciário, coloca-se como questão premente a de sua assimilação, ou seja, a conversão do estatuto de imigrante em brasileiro, obrigando-o a renegar os seus traços e valores de origem (por serem inadequados) a favor da homogeneidade da nação.

A tolerância do governo anterior no âmbito cultural e lingüístico, que permitia e mesmo incentivava a manutenção, entre os imigrantes, de sentimentos de pertença a uma origem em comum, era vista na Era Vargas como algo que poderia comprometer uma suposta homogeneidade cultural do país. Por isso, o texto se mostra favorável a um controle maior do governo em relação à entrada de novos imigrantes e ao estabelecimento de certas restrições para aqueles que já viviam no país e se mantinham isolados do restante da sociedade e do Estado.

Houve, dessa forma, uma transformação do programa narrativo das leis imigratórias brasileiras, que passaram de uma situação tolerante para uma situação de controle dos imigrantes. A acusação de Oliveira Viana ao "liberalismo" da legislação da Primeira República decorreu da ausência de critérios étnicos para a seleção dos imigrantes, ou seja, não foram nela considerados os aspectos culturais mais vantajosos para o desenvolvimento econômico e cultural do Brasil. Por isso, dissemos que a passagem de um governo para outro correspondeu a uma mudança nos programas narrativos: passou-se de um programa de doação ao imigrante de valores que o auxiliariam no trabalho para um programa de espoliação dos traços culturais e lingüísticos deles.

Segundo o texto, as leis anteriores eram um grande estímulo para a manutenção de sentimentos patrióticos em relação ao país de origem do imigrante. Já na Era Vargas, a lei regulamentava não apenas a entrada dos imigrantes, mas criava mecanismos rigorosos para impedir a concentração dos “elementos estrangeiros” já estabelecidos em 
solo nacional com a finalidade de dificultar a perpetuação dos traços e valores estrangeiros. Além disso, o objetivo, naquele momento, era o de conseguir integrar todos os imigrantes presentes no país para torná-los “verdadeiros brasileiros" que contribuiriam para o seu desenvolvimento. Historicamente, se no governo anterior a imigração era vista como uma solução para o país, na Era Vargas passou a ser encarada como um problema de ordem nacional.

\section{PRoblemas e SOlUÇões REFERENTES À PRESENÇA DOS IMIGRANTES NO BRASIL}

Nesse texto, não se discutia mais se os imigrantes eram bons para o país e como fazer para atraí-los (como na Primeira República). A discussão passou a ser pautada pela questão de saber como assimilar o imigrante, pois a sua integração era considerada uma forma de defender a nação brasileira da ameaça estrangeira. Seria, então, dever da sociedade e do Estado brasileiros, segundo o autor, promover políticas de assimilação (ou nacionalização) dos imigrantes para defender a homogeneidade do país. O autor exemplifica de modo claro qual é o problema nas colônias dos imigrantes:

Um destes núcleos continha 1.072 famílias japonesas e apenas 75 famílias brasileiras, ou seja, 6.190 japoneses para pouco mais de 600 brasileiros. Pode-se imaginar o futuro deste núcleo, o que nos reservaria ele em matéria de nacionalização, dadas as condições extremamente favoráveis em que estava colocado para a constituição, dentro de curto período, de um quisto racial perfeitamente caracterizado (Viana, 1991:388).

Para resolver o problema da presença de trabalhadores estrangeiros em solo nacional, a lei brasileira recorreu, segundo o texto, a dois procedimentos utilizados por outros países. O primeiro foi a proibição de colônias homogêneas (utilizada pela França) e o segundo foi a política de nacionalização dos estrangeiros por meio das escolas (procedimento utilizado nos Estados Unidos) (Viana, 1992:386).

Uma das medidas para dissolver a homogeneidade dos núcleos coloniais foi a determinação de que trabalhadores brasileiros natos deveriam estar presentes em maior número do que o elemento estrangeiro, principalmente se este diferisse muito das "características brasileiras“ (racial, lingüística e cultural). Dessa forma, o autor acreditava que estaria criando uma sociedade brasileira "genuína”:

Estabelecemos a obrigatoriedade de certa porcentagem dos elementos nacionais nos núcleos coloniais que se vierem fundar - o que nos assegurará, nestes centros demogênicos e étnicos, que serão células futuras da nossa nacionalidade e da nossa raça, a presença de um agente permanente de nacionalização, de eficiência segura e imediata (Viana, 1992:386-387).

A obrigatoriedade da formação de núcleos coloniais heterogêneos, com a presença de brasileiros e imigrantes de diversas origens, poderia forçar a assimilação mesmo de grupos ditos não-assimiláveis (como os japoneses e os alemães), na medida em que, na presença de tantas línguas diferentes, os imigrantes se veriam obrigados a utilizar a língua portuguesa como uma língua de comunicação entre os grupos. A língua 
nacional passou a ter, então, um papel fundamental no processo de assimilação dos estrangeiros. Como diz o texto:

Está claro que este agente plástico de nacionalização e abrasileiração dos elementos exóticos, para ser eficiente, deverá ser tanto mais denso e mais numeroso quanto mais diferentes pela raça, pela cultura e pela língua forem os elementos exóticos componentes dos núcleos. Daí, o princípio de que a porcentagem dos elementos nacionais deve ser aumentada para aqueles núcleos em que preponderem etnias não latinas, tais como as germânicas, as eslavas e, principalmente, as asiáticas (digamos: a japonesa) (Viana, 1992:387).

Observamos, então, que a relação entre Estado/sociedade e imigrantes passou por uma transformação: anteriormente valorizados, os imigrantes eram, naquele momento, elementos que, com a suposta homogeneidade de seus núcleos coloniais (caracterizados pelo termo “quistos raciais”), poderiam desestabilizar o caráter homogêneo da nação brasileira. Os imigrantes que não se adequassem aos novos valores colocados em jogo, passariam a ser considerados, dentro do programa narrativo, como anti-sujeitos passíveis de punição pelo destinador-julgador.

O texto estabelece a distinção entre imigrantes “desejáveis” e imigrantes “indesejáveis”. Os imigrantes indesejáveis na Era Vargas eram aqueles de difícil assimilação e, conseqüentemente, os desejáveis eram aqueles que poderiam se integrar à sociedade. Além disso, o texto classifica claramente os dois tipos de imigrantes: de um lado, os imigrantes ibéricos (portugueses e espanhóis) e, do outro, os imigrantes de outras regiões (principalmente alemães e japoneses). E essa classificação possui um critério claramente identificável, afinal, para um imigrante que utilizasse a língua portuguesa ou uma língua latina, seria muito mais fácil se integrar à sociedade, ou seja, ser assimilado.

A homogeneidade brasileira, enquanto um valor a ser defendido, se baseava nos traços da cultura latina herdada da colonização portuguesa, entre os quais podemos colocar a língua portuguesa. Por isso, os ibero-latinos poderiam ser utilizados, como dissemos, nas colônias quando o número de brasileiros não comportasse o mínimo estabelecido em lei. A escolha pelos espanhóis e portugueses decorria da aproximação lingüística desses dois grupos imigrantes com o português falado no Brasil. Na tentativa de assimilar os estrangeiros, tal como foi promovida pelo Estado, os portugueses e os espanhóis se configuravam também como adjuvantes na busca da nacionalização dos outros grupos imigrantes. Em relação às estratégias da alteridade, propostas por Landowski (2004:38-40), os imigrantes ibéricos seriam o grupo dos que querem ser assimilados (os “esnobes”), enquanto os outros imigrantes (japoneses e alemães) seriam os que desejam ser segregados (os “ursos”) ou excluídos.

É por essa proximidade da língua e da cultura que no texto se propõe a inserção de portugueses e espanhóis, quando não fosse possível a presença, em quantidade prevista pela lei, de brasileiros natos nas colônias. Para o autor, a lei não deveria ser tão rígida no que se refere a porcentagens de cada etnia. Dever-se-ia realizar uma distinção entre os imigrantes que pudessem ser assimilados e os que não pudessem e não quisessem se tornar brasileiros. Para provar que a sua proposta de "flexibilização" da lei em relação aos imigrantes ibéricos seria boa para o país e para a sociedade, o autor, no 
trecho abaixo, mostra que os imigrantes portugueses e espanhóis já presentes no país se assimilaram de tal forma que não possuem qualquer tipo de distinção em relação aos brasileiros.

Daí termos admitido que, na falta do elemento nacional, pudesse ele ser suprido ou completado com colonos de origem espanhola e portuguesa. Pela sua afinidade com a nossa gente e, principalmente, pela identidade ou semelhança da língua, das tradições e do gênio, não constituem, realmente, os colonos destas duas últimas etnias, nenhum problema sério no ponto de vista da assimilação, sabendo-se que os seus descendentes se mostram tão integrados na nossa comunidade nacional quanto os brasileiros da velha estirpe (Viana, 1992:387).

O texto aponta a língua portuguesa como um dos principais instrumentos para a assimilação dos imigrantes, por ser considerada como um dos elementos constituintes da nação. Preocupava-se, pois, com a possibilidade de o governo brasileiro assimilar de qualquer maneira os imigrantes para não haver um desequilíbrio na formação cultural, lingüística e étnica da nação brasileira.

Além de ser um instrumento no processo de assimilação dos imigrantes, podemos observar que a língua também é utilizada como um valor no programa narrativo do governo brasileiro, a ser defendido contra o que era considerado o fazer de um anti-sujeito, representado pelo “enquistamento” e pela manutenção da língua estrangeira, principalmente na forma em que existia nos Estados de Santa Catarina (com os alemães) e São Paulo, Amazonas e Mato Grosso (com os japoneses, segundo o texto). Como se encontra no texto, a assimilação sistemática dos estrangeiros devia então passar pela "defesa da língua nacional, única coisa que, neste contato de etnias e culturas, está em nosso poder conservar e defender” (Viana, 1991:387).

Para combater a homogeneidade dos núcleos coloniais e promover a nacionalização dos imigrantes, ou seja, a sua assimilação, a convivência diária com brasileiros natos e com imigrantes ibéricos, por si só, não era suficiente. Por isso, o texto defendia a proposta do Estado de nacionalizar as escolas localizadas nos núcleos coloniais para a constituição da futura nacionalidade brasileira. Essa nacionalização seria uma complementação ao processo de assentamento de brasileiros nos núcleos coloniais que auxiliaria na assimilação dos estrangeiros (Viana, 1991:386). Os filhos dos imigrantes poderiam, dessa forma, receber uma educação formal nas matérias que interessavam ao Estado e à sociedade. Essa seria a maneira encontrada para inserir o elemento cultural brasileiro nas famílias imigrantes (principalmente as de origem nãoibérica), interferindo nas possíveis tentativas de manutenção dos valores de origem estrangeira. Assim, os imigrantes não apenas deveriam falar a língua portuguesa, mas também passariam a aceitar os valores brasileiros em detrimentos de seus valores de origem.

A escola passou a ser mais um adjuvante para auxiliar na construção da nacionalidade brasileira. Seria pelo conhecimento da língua portuguesa (e da história e da geografia brasileiras também) que os filhos de imigrantes se assimilariam à sociedade brasileira e, por conseguinte, deixariam de usar a língua e de preservar os costumes de origem de seus pais. Em outras palavras, a escola auxiliaria na transformação do sujeito, de um não-saber-ser para um saber-ser (brasileiro). 
Assim, não ocorreriam mais episódios como nos “[...] núcleos germânicos de Santa Catarina, em que brasileiros, descendentes de alemães, ignoravam a língua da sua pátria, sem possibilidade de se entenderem com os seus compatriotas que falavam o português" (Viana, 1991:388). Ou ainda, no caso dos japoneses, "em que, para oito escolas primárias, havia seis professores brasileiros e 16 professores japoneses, estes falando em japonês e ensinando as crianças japonesas, na sua maioria filhos de japoneses nascidos no Brasil; portanto, brasileiros” (idem).

Podemos, ainda, considerar esse discurso preconceituoso porque não aceitava os valores do outro e, assim, construiu uma imagem negativa dos imigrantes (ser malevolente) e é também intolerante porque propõe ou faz algo para eliminar os traços culturais e lingüísticos dos trabalhadores imigrantes (fazer malevolente). A crítica à tolerância e à liberalidade do governo da Primeira República, estabelece, por meio da interdiscursividade, um recurso para se justificar os valores apresentados e defendidos pelo texto ao "denunciar" a tolerância como a postura causadora da presença e permanência de estrangeiros que não queriam se integrar à sociedade brasileira.

\section{CONCLUSÃo}

Ao usar a língua portuguesa como um valor nacional a ser defendido, o autor mostrou como a presença dos imigrantes e de suas línguas podia ser considerada ruim para o Brasil. Caberia ao governo elaborar estratégias (dissolução de núcleos coloniais homogêneos e obrigatoriedade do uso e do ensino da língua portuguesa nas escolas existentes nos núcleos coloniais) para assimilar os estrangeiro e, assim, impedir qualquer tipo de ameaça à integridade nacional.

A intolerância lingüística presente no texto (que utiliza a língua nacional como um valor e como um mecanismo para assimilar o outro, apagando ou eliminando as diferenças), serve como uma proposta para se forçar a transformação do imigrante em brasileiro (dever-ser). A língua portuguesa tem papel essencial na operação de integração de estrangeiros que tinham comportamento diferente do dos brasileiros (não apenas em relação à língua) e que aparentemente, segundo o texto, não pretendiam mudá-lo.

O texto de Oliveira Viana é, portanto, aquele em que os sujeitos-imigrantes (ou determinados grupos) recebem uma sanção negativa por parte do destinador-julgador por não cumprirem o contrato estabelecido anteriormente (que, como dissemos, havia mudado de um regime político para outro). Assim, os imigrantes recebem uma sanção negativa e devem aceitar as condições de um novo contrato fiduciário, ou seja, o de se tornarem brasileiros (por meio da assimilação). Para o estabelecimento desse novo contrato, a intimidação tem forte presença, uma vez que houve a imposição, por meio da lei e da concordância de parcela da sociedade, da obrigatoriedade dos imigrantes se tornarem brasileiros.

Por fim, o texto de Oliveira Viana possui os traços de um discurso nacionalista, ao reafirmar a soberania nacional sobre os estrangeiros residentes em solo brasileiro. Por isso, imigrante bom era um imigrante assimilado (isto é, aquele que deixava de ser imigrante), e aqueles que se isolavam do restante da sociedade (por razões lingüísticas e culturais) eram automaticamente colocados do lado dos imigrantes indesejáveis. 
Até que ponto os objetivos dessa política lingüística foram alcançados está além do alcance desse trabalho. Podemos dizer, contudo, que os descendentes de imigrantes estão, ao menos aparentemente, integrados, as línguas estrangeiras continuam a ser utilizadas em determinadas situações dentro do país (sem causar maiores constrangimentos a quem as utiliza) e, o mais importante, a idéia de homogeneidade brasileira foi, ao menos parcialmente, descartada para dar lugar à idéia de heterogeneidade como característica da cultura nacional.

\section{NotAS}

${ }^{1}$ Não sabemos ao certo se o texto original foi impresso com esse erro tipográfico ou se isso ocorreu apenas no texto a que tivemos acesso. Contudo, está claro que o autor se refere à Constituição de 1914 e não de 1941, mesmo porque se criaria um problema de coerência.

\section{REFERENCIAS BIBLIOGRÁFICAS}

BARROS, Diana Luz Pessoa de. Teoria do discurso. São Paulo, Editora Atual, 1988.

HÉRITIER, Françoise. "O eu, o outro e a intolerância". In: A Intolerância. BarretDucrocq, F. (org.). Rio de Janeiro, Bertrand Brasil, 2000.

LANDOWSKI, Eric. Presenças do outro. São Paulo, Editora Perspectiva, 2002.

RICOEUR, Paul. "Etapa atual do pensamento sobre a intolerância”. In: A Intolerância. Barret-Ducrocq, F. (org.). Rio de Janeiro, Bertrand Brasil, 2000.

VIANA, Oliveira. "Imigração e Colonização Ontem e Hoje”. In: Ensaios Inéditos. Campinas, Editora da Unicamp, 1991. (original publicado em 1943).

\section{Como citar este artigo:}

BUENO, Alexandre Marcelo. O estado novo e sua relação com os imigrantes: a língua como defesa dos valores nacionais. Estudos Semióticos. [online] Disponivel na Internet via WWW.URL: http://www.fflch.usp.br/dl/semiotica/es.

Editor Peter Dietrich, Número 4, São Paulo, 2008. Acesso em "dia/mês/ano". 